\title{
Quando os subalternos falam das subalternas
}

\author{
When male non-subalterns speak about female subalterns
}

\author{
TERESA TOLDY (iD)
}

\section{Resumo}

O presente artigo pretende ensaiar uma crítica ao discurso da Igreja Católica acerca das mulheres à luz do conceito de subalternidade proposto por Spivak, nomeadamente identificando os silenciamentos das vozes das subalternas através da sua ausência discursiva e do conceito de representação/substituição das vozes das mesmas por um discurso não-subalterno, prescritivo dos papéis sociais das mulheres segundo os documentos do Vaticano.

Palavras-chave: Subalternidade. Catolicismo. Maternidade. Teologias feministas.

\section{Abstract}

This paper aims to develop a critique of the discourses of the Catholic Church about women. This critique is based on Spivak's notion of "subalternity". It will identify the silencing of the voices of subalterns through their discursive absence and the use of the concept of representation/replacement of their voices by a non-subaltern discourse, a prescriptive discourse on the social roles of women according to the documents of the Vatican.

Keywords: Subalternity. Catholicism. Motherhood. Feminist Theologies.

\section{Introdução}

Em 2013, o Papa Francisco (SANTA SÉ, 2013, p. 9-10) na conferência de imprensa a bordo do avião de regresso a Roma, vindo das Jornadas Mundiais

\footnotetext{
a Universidade Fernando Pessoa, Porto, Portugal/ Faculdade de Economia da Universidade de Coimbra, Coimbra, Portugal. Doutora em Teologia, e-mail: toldy@ufp.edu.pt 
da Juventude, no Rio de Janeiro, fez um conjunto de afirmações acerca das mulheres dignas de nota. Quando um jornalista lhe perguntou se seria possível uma mulher vir a ser nomeada para presidir a um dicastério, o Papa começou por dar uma resposta surpreendente:

O papel das mulheres na Igreja não é só a maternidade, a mãe de família, mas é mais forte: é precisamente o ícone da Virgem Maria, de Nossa Senhora; aquela que ajuda a Igreja a crescer. [...] Paulo VI escreveu uma coisa bonita sobre as mulheres, mas acho que se deve avançar mais na explicitação deste papel e carisma da mulher. Você não pode entender uma Igreja sem mulheres, mas mulheres ativas na Igreja, com o seu perfil, que fazem avançar.

E acrescentou: "Na Igreja, temos de pensar a mulher sob essa perspectiva de escolhas arriscadas, mas como mulheres" (SANTA SÉ, 2013, p. 9-10). Pelo que concluiu dizendo:

Eu acho que ainda não se fez uma profunda teologia da mulher na Igreja. Limitamo-nos a dizer que pode fazer isto, pode fazer aquilo, agora faz a coroinha, depois faz a Leitura, é a presidente da Caritas... Mas, há muito mais! É necessário fazer uma profunda teologia da mulher (SANTA SÉ, 2013, p. 9-10).

Ainda em 2013, nos 25 anos da Mulieris Dignitatem, de João Paulo II (a primeira Carta Encíclica sobre "a mulher" - e sublinho o singular — "a mulher"), Francisco voltou a dizer que "é importante perguntar-se que presença tem a mulher" (FRANCISCO, 2013). E acrescentou: "A Igreja é feminino, é mãe”. "Devemos aprofundar a nossa compreensão disso” (idem).

Este texto não pretende negar a relevância da política de introdução de mulheres em lugares de bastante relevo na Igreja Católica levada a cabo por Francisco (como seja, por exemplo, a nomeação no presente ano de 2020 de uma mulher (Francesca Di Giovanni) para subsecretária da Secção para as Relações com os Estados (RADIO VATICANO, 2020). O que se pretende realçar é o facto de, apesar disso, o discurso sobre as mulheres parecer não ter mudado: continua a ser um discurso de uma normatividade que perpetua a enunciação das mulheres (melhor, “da mulher”) como objeto de reflexão por parte da hierarquia da Igreja Católica, e não como sujeito, isto é, recorrendo às categorias de SPIVAK (1988; 2005) nas quais a argumentação do presente texto se baseia, continuam a ser os não-subalternos a enunciar discursos sobre as subalternas. 


\section{Silêncio e silenciamento}

A afirmação de que "é necessário fazer uma profunda teologia da mulher" (SANTA SÉ, 2013, p. 10) poderá ser interpretada de várias formas. Parece que, por um lado, revela uma ignorância total (voluntária ou involuntária) da produção teológica feminista, cujos primeiros passos, de maneira mais formal, podem ser identificados com a geração do Concílio Vaticano II (por exemplo, BOERRESEN, 1968; DALY, 1973, FIORENZA, 1964; HEINZELMANN, 1967; RAMING, 1973; RUETHER, 1974); e, por outro lado, parece manifestar o desejo de uma" teologia do feminino", algo completamente diferente de uma teologia feminista 1 . O âmago da diferença entre uma teologia (feminina) e outra (feminista) está, precisamente, entre as diversas interpretações das experiências do transcendente enunciadas por mulheres (ou por homens) como algo emancipatório, e uma teologia essencialista na qual não se fala de mulheres, mas sim "da mulher". É essa perspetiva essencialista que constitui a divergência nuclear entre teologias feministas e teologias femininas e é esta última que informa o discurso da hierarquia da Igreja Católica, expressa continuadamente nos documentos emitidos pelo Vaticano ${ }^{2}$. As vozes das teologias feministas parecem nunca ter sido ouvidas no Vaticano. A ignorância das terminologias usadas pelas mesmas, dos seus pontos fulcrais, da espiritualidade que as inspira parece ser total, porque não transparece no discurso dos documentos mencionados. $\mathrm{O}$ mesmo se diga de toda a discussão acerca das questões do género que constitui objeto atual dos documentos do Vaticano e que revela uma

\footnotetext{
1 Para uma panorâmica das teologias do feminino, ver: DERMIENCE, 2000.

2 Veja-se a título de exemplo, JOÃO PAULO II, Adhortatio Apostolica "Familiaris Consortio", in: AAS 74 (1982) 81-191; Epistolae Apostolicae "Mulieris dignitatem", in: AAS 80 (1988) 16531729; SACRA CONGREGATIO PRO DOCTRINA FIDEI, Commentaire au sujet de la Déclaration de la Congrégation pour la Doctrine de la Foi sur la question de l'admission des femmes au sacerdoce ministériel, in: DC 1714 (20.02.1977) 165-173; Declaratio circa quaestionem admissionis mulierum ad sacerdotium ministeriale. Inter insigniores, in: AAS 69 (1979) 98116. PONTIFICAL COUNCIL FOR THE FAMILY, Lexicon. Ambiguous and debated terms about family, life and ethical matters. Front Loyal: Human Life International, 2006. BENTO XVI, Adress to the German Bundestag, Berlin (22 setembro 2011)", in: AAS 103 [2011:10, 668. Para referências críticas ver: HENRIQUES; TOLDY (2012); TOLDY; GARRAIO (2020); GARRAIO; TOLDY (2020); CASE (2016).
} 
ignorância querida ou não dos debates fulcrais, uma ignorância resultante do facto de as autoras e os autores fundamentais para o debate nunca serem citados - não lhes ser atribuído estatuto de parceiras e parceiros na discussão do tema ${ }^{3}$. Não há documento do Vaticano que cite teólogas feministas ou autores e autoras de referência para o debate em torno da questão do género. As suas vozes não se fazem ouvir. É um avanço digno de nota a existência de uma página mensal no Osservatore Romano dedicado às mulheres na qual a maior parte dos colaboradores são mulheres, mas isso não significa que as vozes de mulheres que começam a ouvir-se sejam declaradamente feministas. Nesse sentido, seria ilusório pensar que a teologia feminista chegou ao Vaticano. Não chegou. Chamo a atenção para um texto publicado precisamente no Osservatore Romano, no dia 1 de Dezembro de 2014, intitulado "Para uma profunda teologia da mulher", que constitui um debate passado a escrito entre teólogos e teólogas no qual se revelam ambiguidades conceptuais entre os termos "feminino" e "feminista" (OSSERVATORE ROMANO, 1 de Dezembro de 2014), bem como para a triste notícia, divulgada no dia 1 de Abril de 2019, de que Lucetta Scaraffia e a equipa editorial deste suplemento sobre as mulheres (Donne Chiesa Mondo) se haviam demitido, por se sentirem "cercadas por um clima de desconfiança e deslegitimação progressiva" (MARUJO, 2019).

Seria também um erro pensar que o tema do feminismo na teologia apareceu agora, quando autores homens começam a falar de Deus utilizando metáforas femininas (a ideia de Deus como Mãe, por exemplo4), um debate com trinta anos de atraso em relação à produção teológica feminista ${ }^{5}$, mas que parece não só enfermar de uma ignorância supina e programática dos debates fundamentais das teologias feministas, como também da repetição do mesmo raciocínio que impede que as vozes das mulheres se façam ouvir. Esse erro consiste na convicção de que o discurso sobre "a mulher" ou sobre as "mulheres" só é válido quando enunciado por homens e, de preferência,

\footnotetext{
${ }^{3}$ Ver nota 2.

${ }^{4}$ Veja-se, a título de exemplo uma entrevista dada por BORGES (2015) e TAMAYO (2011).

5 Cf. a título de exemplo, ACHTEMEIER (1992); BROCKMANN (1987); DALY (1973); GROSSMANN (1988); HALKES (1981); JOHNSON (1992) MACFAGUE (1989); MOLLENKOTT (1985); RUETHER (1981).
} 
clérigos. Esta perpetuação de um discurso essencialista pode ser alimentada também por mulheres.

\section{Produção discursiva de subalternidades}

Os pressupostos teóricos da presente análise não são teológicos. A leitura continuada de textos produzidos pelo Vaticano e repetidos acriticamente ou por convicção leva-me a ensaiar uma interpretação dos mesmos com recurso ao conceito de "subalternidade", de SPIVAK, particularmente no seu texto - um clássico dos estudos pós-coloniais e não só (visto que será utilizado num contexto completamente diferente, como é óbvio) - intitulado: “Can the Subaltern Speak?”(CSS) / "Pode o subalterno falar?", publicado em 1988, e o seu texto "Scattered speculations on the subaltern and the popular" (SSSP), de 2005. É uma tentativa arriscada — não o escondo - porque constitui uma translação, bem como uma tradução do seu conceito de subalternidade e das relações de poder que o mesmo envolve para um corpus textual e para uma realidade que lhe são alheios. Animou-me a ensaiar esta tentativa o próprio conceito de "subalterno" formulado por SPIVAK. Subalterno é "aquele que é removido de todas as linhas da mobilidade social" (SSSP, 475), ou, no segundo texto referido, "a subalternidade é onde as linhas sociais da mobilidade, estando num outro sítio, não permitem a formação de uma base de ação identificável” (SSSP, p. 476). Contudo, estou também consciente de que o recurso a este conceito de "subalternidade" não pode ser interpretado univocamente: é preciso não esquecer a perspetiva dos estudos interseccionais, segundo a qual, a subalternidade constitui como que um "feixe de exclusões" — de sexo, de raça, de classe social (ver CRENSHAW, 1991; KIM e SHAW, 2018). Quero com isto dizer que "o lugar da subalterna” (utilizarei o feminino da palavra, porque é da subalternidade de mulheres que se trata) pode possuir contornos abissalmente diferentes dependendo do contexto geopolítico e geocultural. Neste sentido, fica-se com a sensação de apropriação de um conceito com implicações muito díspares, o que, neste momento, também cria cenários e angústias diferentes mesmo para aquelas e aqueles que são católicas e católicos: a quem devemos atender? Aos pobres 
ou às mulheres? Esta pergunta, em concreto, não é de resposta muito difícil, porque a maioria dos pobres são mulheres e crianças. Mas podemos também pensar: o que é mais importante? Atender aos pobres, denunciar o sistema capitalista gerador de uma injustiça sem limites ou desejar que as mulheres possam ser ordenadas na Igreja Católica? Não irei por esse caminho, mas sim pelo trilho da produção discursiva de subalternidades nos documentos do Vaticano e de teólogos (e também de teólogas!), o que, no texto-matriz de Spivak corresponde ao debate em torno de estruturas de poder e da capacidade e estatuto de quem enuncia o quê.

No seu texto "Can the subaltern speak", a questão coloca-se relativamente ao papel do intelectual na representação do trabalhador (SPIVAK debruça-se sobre o discurso marxista através da referência ao próprio, bem como a um texto de Foucault e Deleuze sobre os “Intelectuais e [o] poder"). Coloca-se a questão de os intelectuais poderem falar em nome de quem não tem voz, de quem não consegue fazer-se ouvir e, como tal, necessita de "porta-vozes", de "representantes". Ora a representação pode ser entendida como este "falar por alguém" (no sentido político de "representar alguém”) ou como “re-representação", isto é, como interpretação do que esse alguém não articula (porque não sabe, porque não pode, porque não lhe é dado lugar para tal) e está apenas na posição de "articulado". A ideia de representação ou do "representante" significaria que "o sujeito não é considerado como possuindo uma consciência representativa" (CSS, 70) e precisa de ser “substituído" por alguém que sabe enunciá-lo. Este jogo de representação e de "re-representação" (isto é, interpretação) torna o representado alguém "transparente", invisível. Ele não existe como uma entidade real produtora de uma discursividade - só existe o discurso que o “representa”. Contudo, quando o jogo é visto do lado oposto, o “intelectual que representa e re-representa" o representado também se torna transparente: ele "limita-se" a relatar o sujeito não-representado, melhor, ele possui e cria a ilusão da reprodução exata da realidade do outro. Spivak considera "a constituição do sujeito colonial como Outro" o "exemplo mais claro desta violência epistémica" (CSS, 76). Embora não seja a questão colonial que aqui nos ocupa, a descrição da violência epistémica como "a obliteração assimétrica do rasto do Outro na sua subject-ividade precária" (CSS76), na sua 
constituição como sujeito, patente na narrativa da história da Europa, invisibiliza e silencia "a narrativa palimpséstica do imperialismo", o reconhecimento de "um conhecimento subjugado, uma série de conhecimentos que foram desqualificados como desadequados para cumprir a sua tarefa ou elaborados de forma insuficiente: conhecimentos ingénuos, no nível mais baixo da hierarquia, abaixo do nível de cognição ou cientificidade requeridos" (CSS, p. 76).

\section{Obliterações assimétricas}

Ensaiar a aplicação desta estrutura de subjugação epistémica patente na "representação" e "re-representação" ao universo discursivo que aqui nos ocupa - isto é, o discurso da hierarquia da Igreja Católica acerca "da mulher" — significa dizer que a fala e os conhecimentos das mulheres não são tidos em linha de conta. Também eles sofrem uma "obliteração assimétrica", produzida por discursos supostamente "interpretativos" da sua realidade, que tornam transparentes os não-subalternos (produtores do discurso) e as subalternas. Os não-subalternos, porque o seu discurso é apresentado como "a realidade". As subalternas, porque a sua realidade não existe, é ignorada, engolida pela "re-representação". A sua voz não se ouve. Antes, é substituída ("representada") por uma "explanação e uma narrativa da realidade estabelecidas como normativas" (SPIVAK, CSS, 76).

Mas Spivak coloca-se a mesma pergunta acerca da possibilidade de os subalternos falarem ou não também a partir das "margens", ou, como ela diz, "do centro silencioso, silenciado" (CSS, 78). No que às mulheres diz respeito, segundo a autora, "a possibilidade de um coletivo, em si, é obstaculizada persistentemente por uma "manipulação da agência feminina" (CSS, 78). E aqui, Spivak introduz uma série de questões que me parecem muito interessantes para o corpus a que me refiro. Diz a autora, a propósito da possibilidade de as elites de países subalternos (refere-se, concretamente, à Índia) funcionarem como uma espécie de reprodução dos mecanismos de nãosubalternidade do Ocidente: "Algumas variedades da elite indiana, quanto muito, são informantes nativos dos intelectuais do primeiro-mundo 
interessados na voz do Outro" (CSS, p. 79). Ensaiando a translação a que me propunha no início do texto, coloco a hipótese de isto corresponder, no tema que nos ocupa, à enunciação de temas relacionados com as mulheres por mulheres cujo discurso não é feminista, mas sim "feminino", audível para os ouvidos vaticanistas, interessados nesse "mistério" que as mulheres constituem (não é rara a referência à "essência feminina" como "mistério" criado por Deus ${ }^{6}$ ). No entanto, prossegue Spivak, “é necessário insistir que o sujeito subalterno colonizado é irremediavelmente heterogéneo" (CSS, p. 79), o que interdita a possibilidade de um discurso-espelho essencialista do/da “subalterno/a". Concretizando um pouco mais a ligação entre este enunciado e os discursos normativos ou neo-normativos (também produzidos por mulheres) do Vaticano: a moeda continua a ser a mesma quando o discurso que "congela a identidade da mulher", em lugar de ser produzido no discurso masculino, é produzido em discursos sobre o feminino.

O ensaio de Spivak aqui apresentado sumariamente, transladando os aspetos que se tocam com o discurso dos não-subalternos acerca das subalternas para os discursos da hierarquia da Igreja Católica, desenvolve uma segunda parte sobre práticas religiosas hindus, nomeadamente, sobre o "sati" - a prática de queimar a viúva juntamente com o cadáver do marido, prática que Spivak não sanciona, obviamente. Mas a questão que ela coloca, a propósito disto mesmo, é desafiadora, uma vez que, do seu ponto de vista, os discursos quer de legitimação da prática, quer de abominação da mesma, sobretudo na literatura inglesa do século XIX, revelam a mesma impossibilidade de audição da voz das mulheres: por um lado, os homens brancos consideram seu dever "salvar as mulheres castanhas dos homens castanhos", provando, assim, a sua superioridade cultural e a sua missão civilizadora (cf. CSS, p. 101). Por outro lado, a mulher imolada é vista pela sociedade hindu como uma "boa esposa" — sati, significa, precisamente, "boa

\footnotetext{
${ }^{6}$ Cf., a título de exemplo JOÃO PAULO II $(1988,22):$ "A Bíblia convence-nos do fato de que não se pode ter uma adequada hermenêutica do homem, ou seja, daquilo que é «humano», sem um recurso adequado àquilo que é «feminino». Analogamente acontece na economia salvífica de Deus: se queremos compreendê-la plenamente em relação a toda a história do homem, não podemos deixar de lado, na ótica de nossa fé, o mistério da «mulher»: virgemmãe-esposa".
} 
esposa". Spivak conclui que: "Não há nenhum espaço a partir do qual o sujeito subalterno sexuado" (as mulheres) possa falar" (p. 103) no conflito violento entre aqueles que estão em posição de "re-presentar/apresentar" (darstellen/ vertreten) "a mulher" como tal. Esta impossibilidade de se fazer ouvir e de ser objeto representado, como já dito, perpetua-se no discurso da hierarquia da Igreja Católica, que assume, até, como sua missão, salvar as mulheres das próprias mulheres, melhor, salvar as mulheres dos movimentos discursivos e praxiológicos de emancipação, uma vez que estes desvirtuam a "essência" do que é "ser mulher" - coisa que é do conhecimento do Vaticano, ao que parece, mas que o Vaticano considera ser necessário recordar às próprias mulheres. A título de exemplo (porque, neste momento, pode falar-se de um corpus substancial de textos produzidos pelos diversos órgãos do Vaticano e por teólogos e teólogas que os sancionam) menciono aqui apenas um exemplo de um documento (no formato de léxico) do Conselho Pontifício da Família (2006), intitulado "Ambiguous and debatable terms regarding family life and ethical questions". Não é aqui o lugar para abordar a polémica em torno do conceito de "ideologia de género" (cf. GARRAIO e TOLDY, 2020; TOLDY e GARRAIO, 2020), que constitui uma discussão com mais contornos do que o tema aqui proposto, embora se cruze com ele. O Léxico aqui referido, na entrada sobre o género diz claramente ao que vem: constitui um compêndio de argumentação contra as abordagens a partir do conceito de género, definido como "estranha dissociação entre o sexo e género, a natureza e a cultura, destrói a dimensão pessoal do ser humano, reduzindo-o à simples individualidade" (BURGGRAF, 2006, p. 399).

No entanto, o que interessa enfatizar aqui é que o discurso considerado "bom" é aquele que os não-subalternos prescreveram para as "subalternas": é aquele que as fixa (como borboletas numa exposição), representando-as como mães. Matlary (2016, p. 609), autora da entrada sobre "Maternidade e Feminismo", inicia o texto com uma invetiva contra o feminismo:

Qual o significado e o lugar da maternidade nos movimentos feministas atuais? As respostas a esta questão estão articuladas em torno de dois polos. Por um lado, nas correntes feministas radicais a palavra maternidade é escondida e, muitas vezes, proibida. [...] A maternidade constituiria um fardo do qual as mulheres quereriam libertar-se, a fim de ocuparem o seu lugar na sociedade de 
produção. Mas, por outro lado, podemos ver um novo feminismo a emergir, que, opondo-se ao feminismo radical redescobre a especificidade feminina e reconhece a dimensão maternal essencial à feminilidade. Baseando-se numa nova investigação antropológica e apoiado em diversas ciências sociais, este novo feminismo especifica o papel essencial das mulheres e das mães na família nuclear. Também nos leva a descobrir o papel determinante da mãe na educação dos filhos. Por fim, revela que a atividade da mãe, se for positiva para o marido e os filhos, também é boa para a sociedade. Este novo feminismo tem o direito a reclamar um estatuto para as mães e reconhecimento por parte das autoridades públicas do seu contributo para a comunidade humana.

Existem nuances no discurso e na prática do Vaticano relativamente às mulheres: quando elas começaram a constituir tema de documentos (com a Mulieris dignitatem, de João Paulo II) as suas vozes não existiam, sequer. Apesar de existirem mais mulheres em postos de decisão (como já referido), podemos perguntar-nos se a matriz não permanece: os não-subalternos dãoIhes voz porque elas valorizam a essência feminina, valorizam a maternidade (física ou espiritual). A voz é-lhes dada, porque correspondem à representação que os não-subalternos têm delas.

\section{Considerações finais}

Poderemos considerar que todo este discurso é académico. Neste sentido, estaremos todas e todos a participar no jogo das "representações", no drama dos intelectuais, de que fala Spivak. O que fazer? Ela própria, afirma a necessidade de "aprender a aprender a partir de baixo, dos subalternos, e não se limitar a estudá-los, a estudá-las" (SSSP, p. 482). O problema continua a ser: como passar do estudar para o aprender? Como passar da subalternidade à igualdade? É uma questão ainda mais dificultada pela repetição acrítica de discursos de não-subalternidade como se fossem discursos de reconhecimento da existência da subalternidade. Neste sentido, quando o discurso passa à ação, quando o discurso aparentemente não-subalterno contribui para o reforço da subalternidade, a questão deixa de ser apenas académica, para ter um impacto real. Acabo com o que me parece um exemplo claro disto mesmo. No dia 19 de Janeiro de 2020, as comunidades religiosas das 
diferentes igrejas da região do Porto (Portugal) 7 fizeram uma oração sobre a violência doméstica. Gostariam que ela chegasse a todas as igrejas do país. Caso não fosse em comunidade, pelo menos, pessoalmente. A oração reza assim:

Pedimos ao nosso Deus que proteja todas as famílias da violência doméstica e ampare aquelas que vivem este sofrimento dentro de suas portas.

É a família que nos sustenta, nos orgulha e nos realiza. Normalmente, amamos a nossa família com o mesmo amor com que nos amamos a nós próprios...

Hoje, rezamos por uma família que se define, se constrói e se une pelo Dom que Deus faz de Si próprio no nosso amor. Assim:

Rezamos por um amor livre, mas comprometido;

Amor gratuito e que também sabe receber;

Amor intenso, mas equilibrado;

Amor apaixonado e ao mesmo tempo consciente...

Rezamos por um amor mais forte do que a fraqueza,

Mais entregue do que pedido,

Mais doado do que um direito.

O Filho de Deus encarnado ensina-nos que todos merecemos ser amados assim. E os outros também merecem ser assim amados por nós.

Hoje pedimos a Deus, Pai de todos nós, pelo seu Filho Jesus Cristo, no Amor do Espírito Santo, que a violência não entre nas nossas casas e todos vivam em paz.

A pergunta final que coloco é esta: como será possível a uma vítima de violência rezar esta oração? Como será possível a Igreja não reconhecer que a assimetria entre homem e mulher, que ela promoveu durante séculos, também tem responsabilidade no que toca à violência dentro da família? Como é possível não reconhecer que a violência existe dentro de famílias cristãs? De facto, repito as palavras de Spivak, para terminar: "Não há nenhum espaço a partir do qual o sujeito subalterno sexuado" (as mulheres) possa falar" (p.103) no conflito violento entre aqueles que estão em posição de "representar/apresentar" (darstellen/vertreten) "a mulher" como tal. A borboleta não consegue sair da exposição. As suas asas estão espetadas num quadro.

\footnotetext{
7 Disponível em: https://www.diocese-porto.pt/pt/noticias/secretariados/crist\%C3\%A3osunidos-contra-a-viol\%C3\%AAncia-dom\%C3\%A9stica-19-jan/
} 


\section{Referências}

ACHTEMEIER, E. Exchanging God for "No Gods": A Discussion of Female Language for God. In: KIMEL JR.; ALVIN, F. (Eds.). Speaking the Christian God. The Holy Trinity and the Challenge of Feminism. Grand Rapids: Wm. B. Eerdmans Publishing Co. 1992, p. 1-16.

BOERRESEN, K. E. Subordination et équivalence. Nature et Rôle de la Femme d'après Augustin et Thomas d'Aquin. Oslo-Paris: Universitetsforlaget, 1968.

BORGES, A. E se Deus fosse mãe? Diário de Notícias on-line, 28 mar. 2015. Disponível em: https://www.dn.pt/opiniao/opiniao-dn/anselmo-borges/e-se-deus-fosse-mae4480785.html. Acesso em: 28 mar. 2015.

BROCKMANN, D. Die Weiblichkeit Gottes. Zu Christa Mulacks Programmatik der Neubestimmung des Göttlichen. In: WACKER, M.-T. (Ed.) Der Gott der Männer und die Frauen. Düsseldorf: Patmos, 1987. p. 70-92.

BURGGRAF, J. Gender. In: PONTIFICAL COUNCIL FOR THE FAMILY, Lexicon. Ambiguous and debatable terms regarding family life and ethical questions. Front Royal: Human Life International, 2006. p. 399-408.

CASE, M. A. The Role of the Popes in the Invention of Complementarity and the Vatican's Anathematization of Gender. Religion \& Gender, v. 6, n. 2, p. 155-172, 2016.

CRENSHAW, K. Mapping the Margins: Intersectionality, Identity Politics, and Violence against Women of Color. Stanford Law Review, v. 43, n. 6, p. 1241-1299, 1991.

DALY, M. Beyond God the Father: Toward a Philosophy of Women's Liberation. Boston: Beacon Press, 1973.

DERMIENCE, A. Théologie de la Femme et théologie féministe. Revue théologique de Louvain, $31^{\mathrm{e}}$ année, fasc. 4, p. 492-523, 2000.

DIOCESE DO PORTO. Cristãos Unidos contra a Violência Doméstica. In: Site da Diocese do Porto, 2020. Disponível em: https://www.diocese-porto.pt/pt/noticias/ secretariados/crist\%C3\%A30s-unidos-contra-a-viol\%C3\%AAncia-dom\%C3\%A9stica-19jan/. Acesso em: 30 jan. 2020.

FIORENZA, E. S. Der vergessene Partner. Grundlagen, Tatsachen und Möglichkeiten der beruflichen Mitarbeit der Frau in der Heilssorge der Kirche. Düsseldorf: Patmos, 1964 .

FRANCISCO. Discurso aos participantes do Seminário sobre a Carta Apostólica «Mulieris Dignitatem» de João Paulo II. Vaticano: Libreria Editrice Vaticana, 12 out. 2013.

GARRAIO, J.; TOLDY, T. “Ideologia de género": origem e disseminação de um discurso antifeminista". Mandrágora, v. 26, n. 1, p. 129-155, 2020. 
GROSSMANN, S. Gottesbilder. In: KASSEL, M. (Ed.), Feministische Theologie. Perspektiven zur Orientierung. Stuttgart: Kreuz, 1988. p. 75-103.

HALKES, C. Motive für den Protest in der feministischen Theologie gegen Gott den Vater. Concilium. Internationale Zeitschrift für Theologie, v. 3, p. 256-262, 1981.

HEINZELMANN, G. Die getrennten Schwestern. Frauen nach dem Konzil. Zürich: Zuerich Interfeminas-Verlag, 1967.

HENRIQUES, F.; TOLDY, T. Desconstruindo antropologias assimétricas. Impossibilia. Revista Internacional de Estudios Literarios 4, p. 18-33, 2012.

JOÃO PAULO II. Epistolae Apostolicae “Mulieris dignitatem”. In: AAS 80, p. 1653-1729, 1988.

JOHNSON, E. She Who Is. The Mystery of God in Feminist Theological Discourse. Nova York: Crossroad, 1992.

KIM, G. J.-S. Intersectional Theology. An introductory Guide. Minneapolis: Fortress Press, 2018.

MARUJO, A. Demissão das mulheres de "Donne Chiesa Mondo" provoca perplexidades e ameaça ideia de reforma. 7Margens, 2019. Disponível em: https://setemargens.com/demissao-das-mulheres-de-donne-chiesa-mondo-provocaperplexidades-e-ameaca-ideia-de-reforma/. Acesso em: 29 mar. 2019.

MATLARY, J. H. Motherhood and Feminism. In: PONTIFICAL COUNCIL FOR THE FAMILY, Lexicon. Ambiguous and debatable terms regarding family life and ethical questions. Front Royal: Human Life International, 2006. p. 609-611.

MCFAGUE, S. Mutter Gott. Concilium. Internationale Zeitschrift für Theologie, v. 6, p. 545-549, 1999.

MOLLENKOTT, V. Gott eine Frau? Vergessene Gottesbilder der Bibel. Munique: Beck, 1985.

OSSERVATORE ROMANO. Para uma profunda teologia da mulher. 1 de Dezembro de 2014 .

PONTIFICAL COUNCIL FOR THE FAMILY. Lexicon. Ambiguous and debatable terms regarding family life and ethical questions. Front Royal: Human Life International, 2006.

RADIO VATICANO. Na Secretaria de Estado uma subsecretária mulher: Francesca Di Giovanni. 15 janeiro 2020. Disponível em: https://www.vaticannews.va/pt/vaticano/ news/2020-01/secretaria-estado-nomeacao-mulher.html. Acesso em: 28 out. 2020. 
RAMING, I. Der Ausschlußs der Frau vom priesterlichen Amt. Gottgewollte Tradition oder Diskriminierung? Eine rechtshistorisch-dogmatische Untersuchung der Grundlagen von Kanon 968 § 1 des Codex Iuris Canonici. Colónia-Viena: Boehlau, 1973.

RUETHER, R. R. Religion and Sexism: Images of Woman in the Jewish and Christian Traditions. Nova Iorque: Simon \& Schuster, 1974.

RUETHER, R. R. Das weibliche Wesen Gottes: Ein religiöses Problem von heute. Concilium. Internationale Zeitschrift für Theologie, v. 3, p. 217-22, 1981.

SANTA SÉ. Visita Apostólica do Papa Francisco ao Brasil. Por ocasião da XXVIII Jornada Mundial da Juventude. Encontro do Santo Padre com os Jornalistas durante o voo de regresso. Vaticano: Libreria Editrice Vaticana, 28 de Julho de 2013.

SPIVAK, G. C. Can the Subaltern Speak? In: NELSON, C.; GROSSBERG, L. Marxism and the Interpretation of Culture (eds). Basingstoke: Macmillan Education, 66-111, 1988.

SPIVAK, G. C. Scattered speculations on the subaltern and the popular. Postcolonial Studies, v. 8, n. 4, p. 475-486, 2005.

TAMAYO ACOSTA, J. J. Otra teología es posible. Pluralismo religioso, interculturalidad y feminismo. Madrid: Herder, 2011.

TOLDY, T.; GARRAIO, J. Gender Ideology: A Discourse That Threatens Gender Equality. In: LEAL FILHO W.; et al. (org.), Gender Equality. Encyclopedia of the UN Sustainable Development Goals. Cham: Springer International Publishing, 2020. p. 1-11. 